\title{
"SHUTTLING" IN ARGIOPE AURANTIA
}

\author{
By F. L. WELLS
}

\section{Harvard Medical School}

"Shuttling: The spider, resting at orb-centre, moves through the web and assumes a corresponding position on the opposite side. Seen almost exclusively in $A$. aurantia. ..." (Psyche, 1936, 43, pp. 11-12). The present paper goes on to discuss the data so far obtained, through observations in the field, concerning this relatively distinctive response pattern.

The effective stimulus to shuttling is here the approximating of a vibrating tuning fork, of 128 or 256 v.d. rate, to the dorsum of the spider, no web intervening or touched by the fork. In 1935 the 128 fork was generally used, in 1936 the 256; in direct comparisons there has not been enough difference in the responses to justify their systematic separation for present purposes. Besides the shuttling behavior, various other kinds of reaction occur to this stimulus in $A$. aurantia, but only spreading, reaching and seizing ${ }^{1}$ are of frequency significant for present purposes. No comparable phenomenon was observed by the writer in the other species concerned, viz. the closely related A. trifasciata, and the Epeiras cavatica, domiciliorum, insularis, stellata, trifolium. To these species previously mentioned in this connection, are to be added $C$. conica and E. strix. ${ }^{2}$

These studies concern the seasons of 1935 and 1936 as above, but the procedures differed somewhat in the two years, and are presented separately.

\footnotetext{
${ }^{1}$ For definitions of these terms, see the paper of above reference. Spreading, reaching and seizing are mutually continuous patterns, and their recording proceeds along the lines of a "rating scale." The notation of such responses under field conditions presents problems similar to those dealt with by R. W. Washburn, J. Genet. Psychol. 1932, 40, 84-89; Psychol. Monographs, 1936, 47, 74-82.

2Taxonomy by advice of Professor Nathan Banks and Miss E. B. Bryant.
} 


\section{Data}

The 1935 observations concern 55 individuals, with 167 fork-to-dorsum responses, on 129 occasions. ${ }^{3}$ The points to be dealt with concern maturation effects, repetitions of stimulus, accessory responses and shuttlings to other than the normal stimulus.

Maturation. It appears that the shuttling pattern is to no little extent a function of the degree of maturation. $A$. aurantia changes in appearance so characteristically in the course of its growth, that statement in these terms should not be too difficult, but the present observations are recorded by date only. The following figures represent the situation with the fork-to-dorsum stimuli where the response involved shuttling, and if shuttling did not occur, the nature of the principal response that was made.

\begin{tabular}{|c|c|c|c|c|c|}
\hline Dates & … & to & $\begin{array}{c}8-1-35 \\
\text { to }\end{array}$ & $\begin{array}{c}9-1-35 \\
\text { to }\end{array}$ & $\begin{array}{c}9-16-35 \\
\text { to }\end{array}$ \\
\hline & & $7-31-35$ & $8-17-35$ & $9-15-35$ & $9-30-35$ \\
\hline
\end{tabular}

\begin{tabular}{|c|c|c|c|}
\hline No. of responses . . . . . . 31 & 75 & 30 & 21 \\
\hline per cent shuttle $\ldots \ldots \ldots .58$ & 17 & 23 & 10 \\
\hline per cent spread .........19 & 40 & 3 & 10 \\
\hline per cent reach $\ldots \ldots \ldots \ldots 6$ & 16 & 23 & 24 \\
\hline per cent seize $\ldots \ldots \ldots \ldots .0$ & 18 & 23 & 28 \\
\hline per cent others .........13 & 7 & 23 & 14 \\
\hline per cent imperceptible $\ldots . .3$ & 1 & 3 & 14 \\
\hline
\end{tabular}

${ }^{3}$ An "occasion" is here a period during which an individual is observed uninterruptedly. Notes of observations on one individual, then on a second individual, then on the first again, would embody three "occasions."

The figures in this report share in the limitations that beset quantitations of behavior generally, "intelligence quotients" for example. Their function is to depict in specially condensed form, the trend of a mass of detail. Even numbers of individuals are approximations. One may perhaps take for granted that an identical appearing individual occupying the same nest, is the same spider; but less so that an $A$. aurantia appearing in a new location has not been previously observed in another one. One night in early September, 1934, a high wind blew from a southerly direction across the area under study. On next visit (9-10-34) nearly all the aurantias had disappeared from a certain portion, and newcomers were plentifully distributed along a stone wall bounding this portion on the north.

The location is some old pasture land in Hopkinton, Mass., 20-25 miles from the writer's domicile and work, which accounts for the irregular periods of observation. In each year, the writer was absent during the latter half of August. 
The meaning of these data is believed to be, essentially, that the response pattern increased in aggressiveness as the summer advanced, and subsequently regressed with the coming of autumn. This is directly represented in the progressive decrease of shuttlings, with increase of seizings until the autumn. The reachings show similar increases followed by decrease. In the spreadings, the first increase represents a stage in the maturing of the attack pattern; the second increase was similarly a phase of regression in the attack pattern. The large proportion of "imperceptibles" during the final period will be noted.

Repetition of stimulus. If the spider has once shuttled, she normally, if undisturbed, returns of herself to the original position after an interval of seconds or minutes (see below, 1936 data). If the fork-to-dorsum stimulus be applied to the spider in the changed position, she normally shuttles back, and this process can be repeated to various extents. Only quite limited trials of this nature were made in 1935, but numbers of shuttling repetitions actually observed were,

times shuttled 2-3-4-5-6-*-20

times observed 9-3-0-1-1-4- 1

(*denotes designation in field notes as "repeatedly".)

The extreme case (8-17-35) was otherwise distinguished. A mature individual, she had been remarked on several previous occasions for an exceptional tendency to drop to the ground when approached, which had made tuning fork observation difficult. In this respect and in the shuttling, she was presenting an immature, regressive type of behavior, at a somatic age when more aggressive patterns were characteristic of her neighbors. When various individuals are observed repeatedly, as in these studies, one comes to recognize distinctive "personalities" in certain of them, sometimes regressive as here, sometimes peculiarly aggressive (cf. 1936 data, below).

Accessory responses. The above individual in the last five trials preceded the shuttling with a slight spreading. In only two instances, in other individuals, was extinction of 
the shuttling responses observed, after 3 and 5 shuttlings respectively; it was then replaced by spreading. The shuttling response appeared to mask the spreading in the less behaviorally matured individuals, but the shuttling being on its way to extinction, the spreading became overt.

A word as to the significance of the spreading pattern. As seen in $A$. aurantia, it commonly involved the first pair of legs only; inviting the anthropopsychic analogy of "stick 'em up" (to a threatening stimulus, as an attacking wasp). A lay observer indeed interpreted this and the reaching movements as "fending off" the fork. Actually, it is here

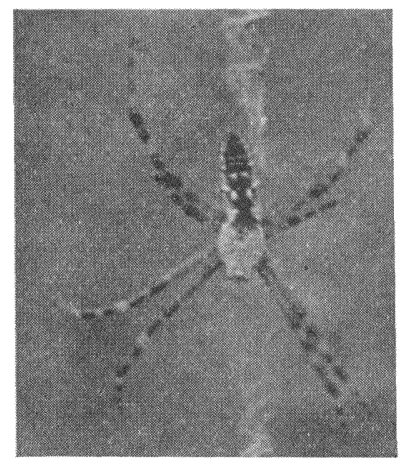

Fig. 1. A. aurantia no. 10 (7-18-36); an individual of specially aggressive response pattern. Note relative size of cephalothorax. The posture, and web stabilimentum are also relatively close to the adult type.

looked on as a frustrated pattern of aggression; of which it is the necessary initial phase, the spider extending the legs preliminary to grasping the prey in them. The reaching pattern represents a transition stage to the fully developed seizing pattern common in the maturer individuals.

One has then, to do with a mixture of the clearly regressive shuttling pattern, and the undeveloped aggression of spreading. In 18 of the above 129 occasions of 1935, the shuttling occurred in combination with one or more of the other response types. In most cases the response in question preceded the shuttling, and naturally, since shuttling removes the spider from the characteristic stimulus. After 
shuttling, the venter is towards the fork, a quite different stimulus situation, having its own patterns of response. On these 18 occasions, shuttling was preceded by spreading in 9 instances; by reaching in 5 instances, by seizing in one instance. In two instances the spider after shuttling, retreated, and in another instance withdrew the abdomen (common response in the young trifasciata). The spreading, reaching and seizing here combine with the shuttling in reverse order of their aggressiveness, but this was not the case in 1936.

Shuttling to other stimulus. In the 129 occasions of present reference, the stimulus is given by the fork approximated to the spider's dorsum, at orb-centre. Other analogous stimuli, to perhaps six times this number, were also applied, including fork vibrating in other positions, and silent but oscillated. Shuttling was observed to stimuli other than vibrating fork-to-dorsum on 9 of these occasions. One of these shuttlings was to a vibrating fork touched to the periphery of the orb; two were on fork-to-dorsum but spider not at orb-centre; two were on the approach of a fork silent but rapidly oscillated. One individual shuttled upon vibrating fork stimuli applied to dorsum, venter and orb periphery. When to venter, it is towards the fork; there was one other instance of this anomalous response. In one instance the shuttling occurred when the fork touched a leg; in another, upon the examiner's mere approach. Fork-todorsum with aurantia not at orb-centre is a situation little observable, but the response to it is probably similar to that at orb-centre.

\section{Data}

During 1933, 1934 and 1935, A. aurantia was abundant in the area concerned. At the close of the 1935 season, eggsacs were found with exceptional readiness. In 1936, the earliest individuals were observed at a date comparable to 1935 (about 3 weeks later than 1934), and in numbers compared well with the young of the two previous years; but although search was carried on with similar care, a scant dozen individuals were observed during this year, that were past the adolescent stage. (The Argiopes seemed more affected than other species; trifasciata especially so.) The total occasions 
involving fork-to-dorsum stimuli is but 50 against 129 of 1935. The amount of observation in the 1936 studies is comparable, being more intensive and controlled than previously.

The following figures are with reference to time of year, tabulated in the same general manner as the 1935 data, by occasion, only one response reckoned per occasion; shuttling if it occurred, otherwise the principal response that was made:

Dates

$\begin{array}{ccc}\begin{array}{c}7-11-36 \\ \text { to } \\ 7-31-36\end{array} & \begin{array}{c}8-1-36 \\ \text { to } \\ 8-15-36\end{array} & \begin{array}{c}9-5-36 \\ \text { to } \\ 9-20-36\end{array} \\ 28 & 11 & 11 \\ 57 & 36 & 9 \\ 7 & 27 & 45 \\ 11 & 9 & 18 \\ 14 & 27 & 18 \\ 0 & 0 & 0 \\ 11 & 0 & 9\end{array}$

The psychology indicated differs somewhat from that of 1935. More in detail; on 7-11-36 four young aurantias were observed for the first time of any that year. In these individuals and one other, the apparent order of somatic maturation was one day later, from least to most, nos. (3), (1), (5), (4), (2). To initial fork-to-dorsum stimulus, (1) and (4) shuttled at once; (2) reached and then shuttled; $(3)$ reached slightly, then dropped to substratum. Response to subsequent (not necessarily in succession) fork-to-dorsum stimuli were:

1 After spontaneous return in 2 minutes, reaching reactions, diminishing to imperceptible (fork 128); spread to fork 256 .

2 Four shuttlings with spontaneous returns, in about 10",45", 4' and $5^{\prime}$ respectively; succeeding four shuttlings preceded by reaches, but no extinction.

3 After return to orb-centre in $5^{\prime}$, seven shuttlings from original position, with time of spontaneous return as follows: $30^{\prime \prime}, 2^{\prime}, 1^{\prime}$, $15^{\prime \prime}, 7^{\prime \prime}, 10^{\prime \prime}, 40^{\prime \prime}$.

4 Four alternate shuttlings and back, all to stimulation; on next stimulus, drop to substratum.

On next observation, 7-12-36, 4 was unavailable, others reacted as follows: 
Spider No.

1

drop 8 in., back in $10^{\prime \prime}$

2 reach, then shuttle, back in $5 "$

3 shake

5 shuttle, back in $1^{\prime}$
Fork-to-dorsum-stimulus No.

\begin{tabular}{|c|c|c|c|}
\hline $\begin{array}{c}2 \\
\text { ack in } 6 \text { in., }\end{array}$ & $\begin{array}{c}3 \\
\text { shuttle }\end{array}$ & $\stackrel{4}{\text { shuttle back } 1}$ & $\begin{array}{c}5 \\
\text { shuttle }\end{array}$ \\
\hline $\begin{array}{l}\text { ch, then } \\
\text { ttle, } \\
\mathrm{k} \text { in } 5^{\prime \prime}\end{array}$ & $\begin{array}{l}\text { reach, then } \\
\text { shuttle, } \\
\text { back in } 1^{\prime}\end{array}$ & shuttle & shuttle back \\
\hline ze, then & shuttle back & shuttle & shuttle back \\
\hline & shuttle back & shuttle & shuttle back \\
\hline
\end{tabular}

Subsequent

1 Changes to reaching, continuing for three successive stimuli by fork 128.

2 Alternate shuttle and back for eight further stimuli, with accompanying spread or reach; later stimuli no shuttle, spread or reaching only, including final stimuli by fork 128 .

3 With one intercurrent exception (shift and shake) seven each alternate shuttle and shuttle back, no reach or spread, no diminution of reactivity.

5 Uncomplicated shuttle and shuttle back for 22 more stimulations, last four to fork 128. Later occasion, this date, 34 responses: shuttling changing to reaching, to fork 256; then repeated shuttling to fork 128; then again shuttling changing to spread to fork 256; then further shuttling and back to fork 128.

In 1935, and in the earlier observations of 1936, the fork was regularly approximated tip to spider's dorsum, long axis of fork about $45^{\circ}$ to vertical axis of orb, moved through a plane at right angles to the plane of the orb. It was noted that in minor asymmetries of stimulation therein arising, the spider uniformly shuttled in a direction away from that of the fork's approach, though the movement might not begin till the fork seemed quite opposite the dorsum. In later observations, principally those of 7-18-36, effort was made at more control of this factor. The fork was held vertical, and moved in a plane parallel to the plane of the orb. The tip of the fork then approached the dorsum either by a lateral movement from right or left (designated L) or downward from above (designated A; location of nests made it impracticable to approach upward from below). In such observations it is vital that no strand of the web be touched by the vibrating fork; often no easy matter, as it is

\footnotetext{
1"Shuttle" denotes movement from normal station; "shuttle back" denotes return to normal station.
} 
the frequent practise of these creatures to put a screen of irregular threads on the side of the orb where they normally rest.

If the shuttling were due essentially to asymmetry of fork stimulation, it should be relatively inhibited in the case of stimulation given as symmetrically as possible. In the 7-18-36 observations, each of the young aurantias available had its first fork-to-dorsum stimulus downward from above. Responses to this and subsequent stimulations were essentially as follows:

Spider No. Stimulus No., Direction and response Subsequent

1

2

4

A reach $\mathrm{L}$ reach spread

A reach, spread

5

A spread

A spread,

L shuttle shuttle back

L reach, spread

$\mathrm{L}$ shuttle and back, then imperceptible; after $1^{\prime}$ one shuttle and back, then refractory to both forks.

9
A seize
L seize
L spread

To 6 subsequent L stimuli: 4 reaches, 2 seizes, no shuttle.

A seize L shuttle

L shuttle

$\mathrm{L}$, to 7 stimuli shuttle and back back, then spread, then imperceptible. Same pattern on two subsequent series this date.

11 A seize A reach

A imperceptible

To 15 subsequent L stimuli, all spread or reach except 1 shuttle, 1 seize.

In these and an added number of other observations prior to August 1, the indication is, that shuttling is somewhat less likely to occur if the stimulus is symmetrical or nearly so. In only one of the 7-18-36 trials of stimulus from above did shuttling occur, and the failure of shuttling in the case of lateral stimulus appears in general a phase of negative adaptation. The uniformity of shuttling in a direction opposite to the fork's approach, is confirmed. The seizings are puzzling. It is hard to exaggerate the violence with which the diminutive creature would literally hurl itself upon the fork, wholly abandoning the nest, and needing to be scraped off the fork for return to the nest. Nothing resembling it 
was seen in the adolescent aurantias of 1935. Stimulus from above (often the only way to give a bilaterally symmetrical stimulus, owing to the "screen") is apparently among the factors, but individual difference at least as much so. The aggressive patterns of $\mathbf{1 0}$ were especially conspicuous (fig. 1).

The following indicates the distribution of responses to all fork-to-dorsum stimuli recorded 7-18-36 to 7-31-36 (9 individuals) :

per cent ........ shuttle spread reach seize other imperceptible

$\begin{array}{lllllll}\text { Stimulus from above (18) } & 11 & 11 & 17 & 33 & 17 & 11\end{array}$

$\begin{array}{llllllll}\text { Stimulus lateral } & (102) & 38 & 13 & 20 & 11 & 12 & 5\end{array}$

These figures compare as follows for responses of 7-12-36 and for those subsequent to 7-31-36 (10 individuals) :

per cent ....... shuttle spread reach seize other imperceptible

7-12-36 (114)

after $7-31-36(52)$
82

$17 \quad 33$

8

8

11

With regard to accessory responses, the situation is similar to that of 1935. Reaching, spreading or seizing may precede the shuttling, but in the 1936 series, the response most frequently combined is reaching rather than spreading. Reaching and spreading again appear, as in 1935, as the shuttling response becomes extinguished. Dropping, a response prominent in the literature of such-like stimulation, is nearly absent from these observations, but from its rare instances, and experience with it in other species, it is surmised to be a response more characteristic than shuttling among individuals younger than have here come to observation.

Only one instance is recorded of shuttling to a stimulus other than fork-to-dorsum; this was on the touching of a leg by an electric vibrator (not the "buzzer" mentioned in the previous report; 11, 8-8-36). This vibrator, made from an electric bell, was little applied as a "to dorsum" stimulus, but gave evidence of being a weaker stimulus than either of the forks.

In conclusion, the evidence for shuttling as a pattern distinctive of $A$. aurantia among the species of present study, 
is briefly reviewed. So far as the other species were available, they were studied in the same manner as $A$. aurantia; but relative scarcity of individuals (e.g., E. stellata) and/or differences of habit (e.g., E. strix) interfere with close comparisons. The following gives the writer's view of the evidence from these observations for the absence of shuttling as a comparable response pattern in the species concerned (there is at hand no evidence of its presence) :

$\begin{array}{lllll} & \text { adolescent } & \text { adult } & \text { day } & \text { night } \\ \text { A. } \text { trifasciata } & \text { good } & \text { good } & \text { only } & \text { none } \\ \text { C. conica } & \text { fair } & \text { good } & \text { only } & \text { none } \\ \text { E. cavatica } & \text { fair } & \text { good } & \text { good } & \text { good } \\ \text { E. domiciliorum } & \text { meagre } & \text { fair } & \text { fair } & \text { fair } \\ \text { E. insularis } & \text { meagre } & \text { good } & \text { X } & \text { only } \\ \text { E. stellata } & \text { meagre } & \text { fair } & \text { only } & \text { none } \\ \text { E. strix } & \text { good } & \text { good } & \mathrm{X} & \text { only } \\ \text { E. trifolium } & \text { meagre } & \text { good } & \mathrm{X} & \text { only }\end{array}$

The apparent absence of the pattern in trifasciata, aurantia's near biological relative, will be noted. C. conica and the Argiopes are normally at orb-centre by daylight; $E$. cavatica, E. domiciliorum and E. stellata may be either at orb-centre or in retreat. E. insularis, strix and trifolium are normally in retreat during daylight. The effect of night on the shuttling behavior of $A$. aurantia also awaits further study; the general tendency of the observations is however, that the behavior of the various species concerned is more aggressive at night. 

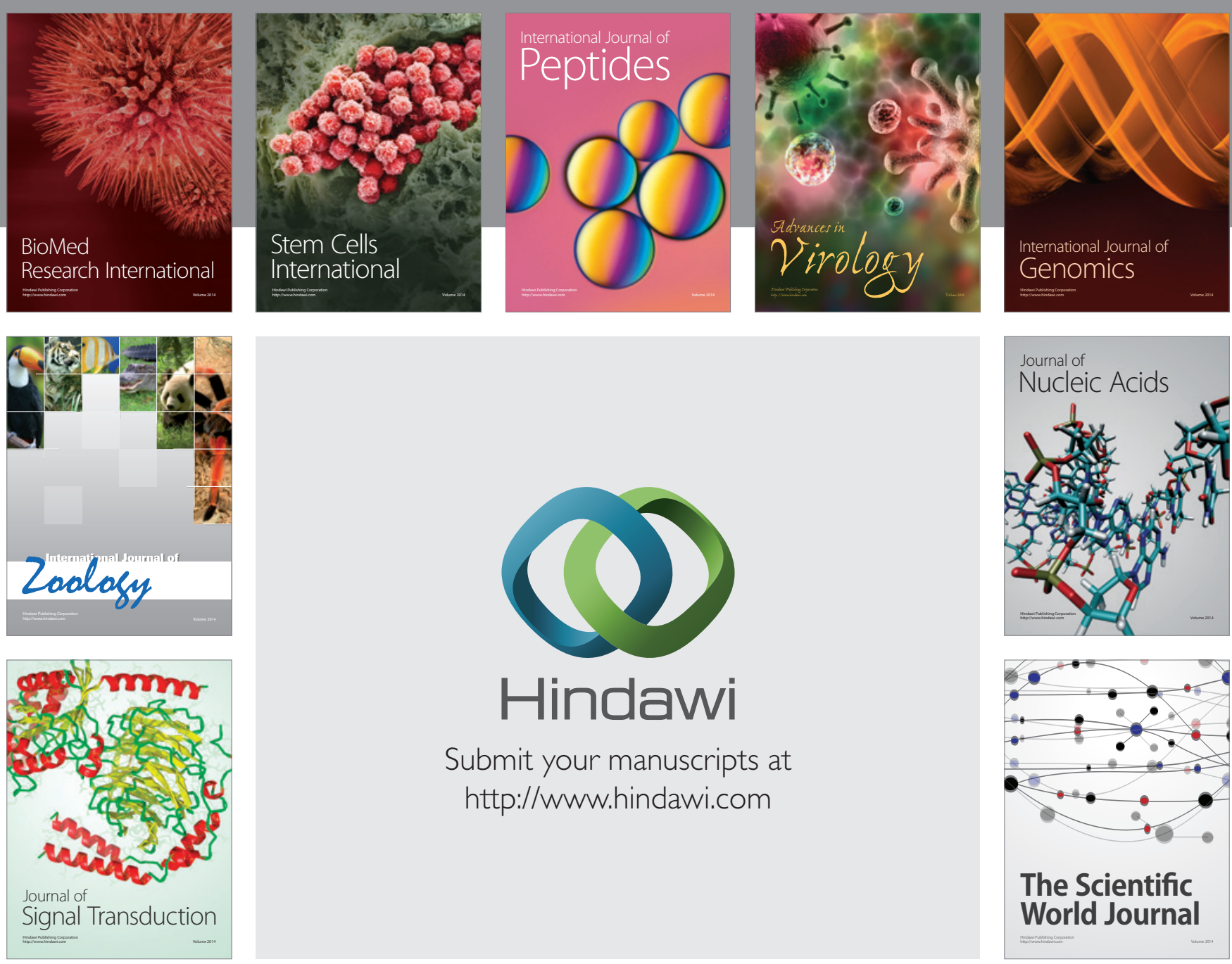

Submit your manuscripts at

http://www.hindawi.com
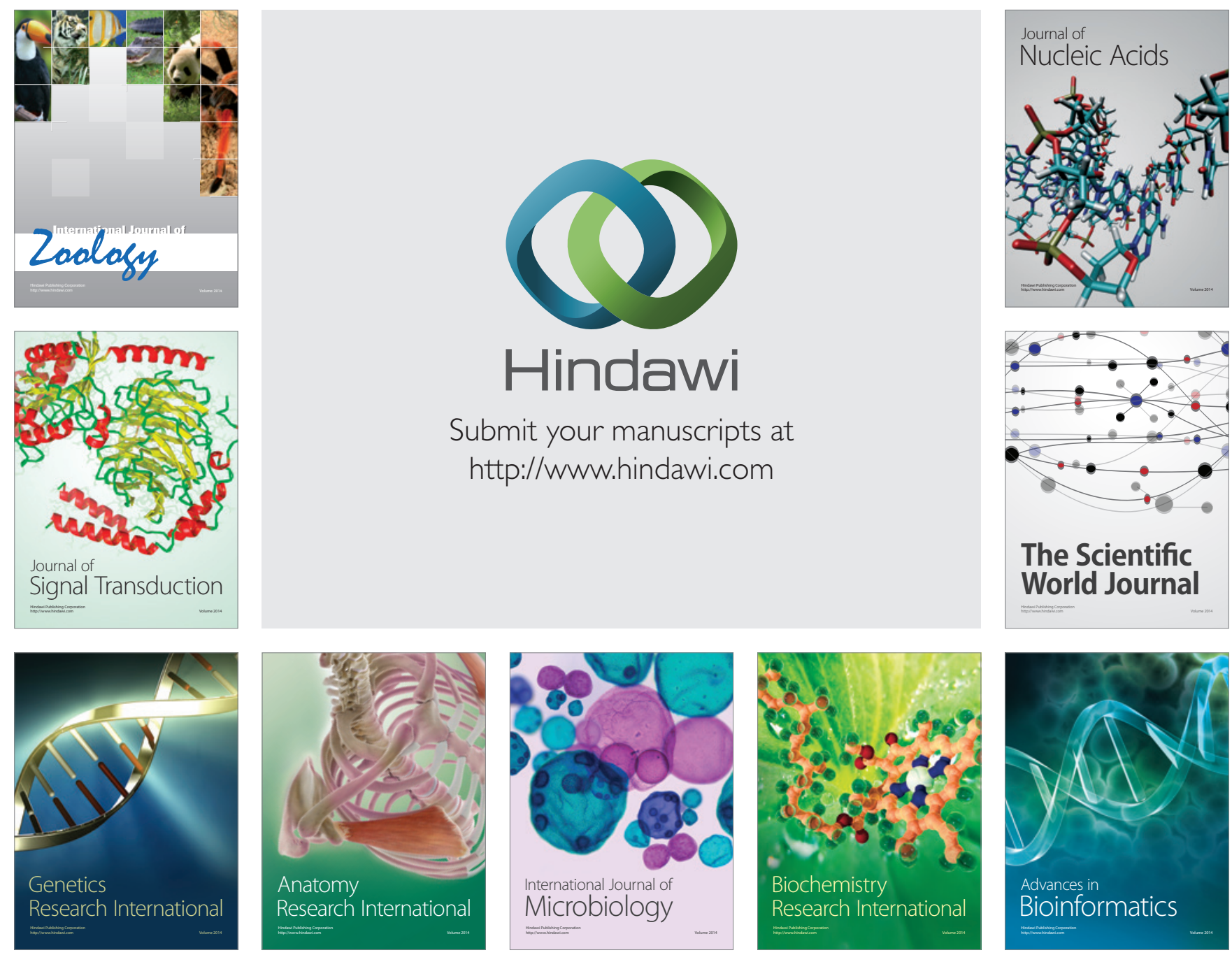

The Scientific World Journal
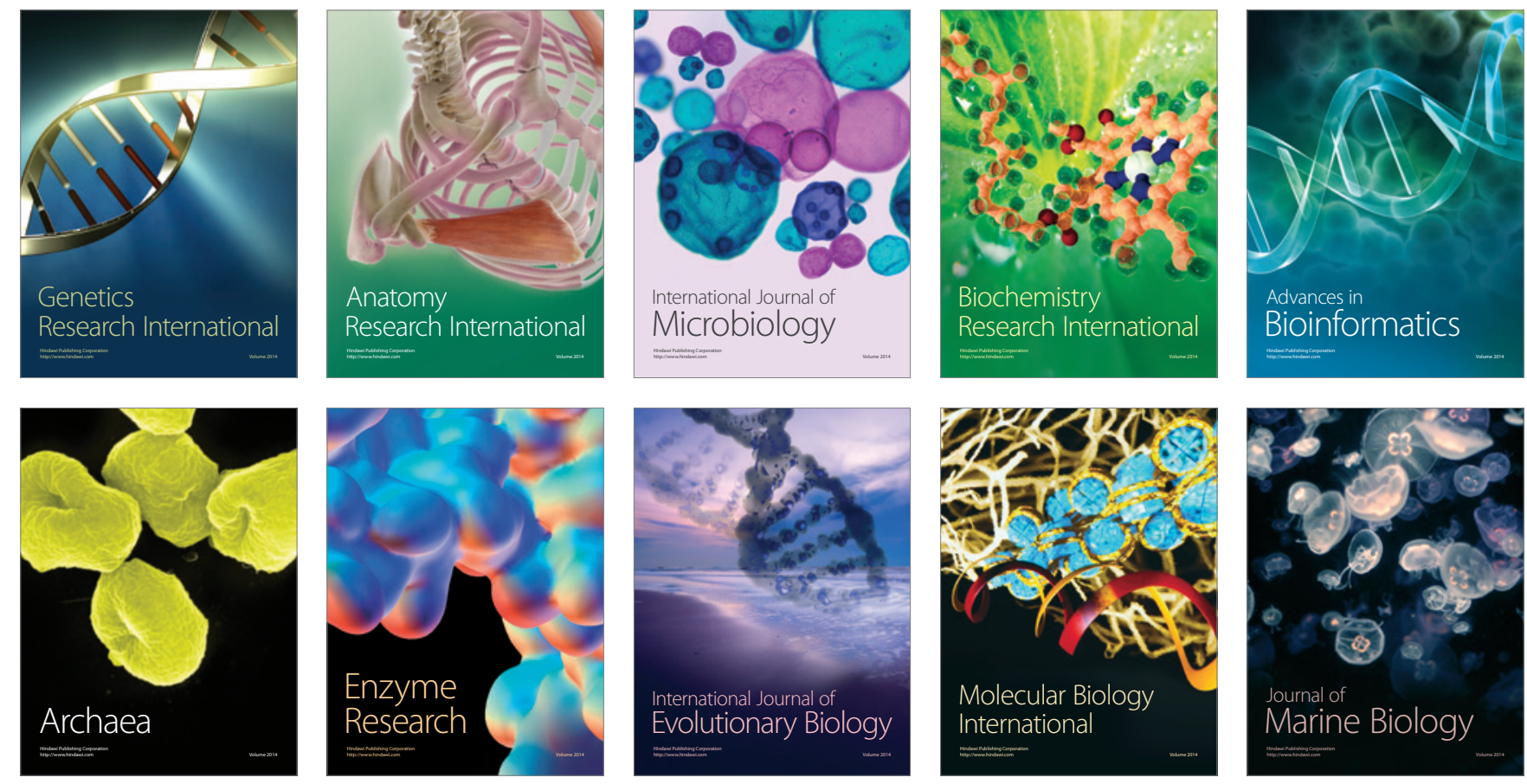